\title{
Tribuna Académica
}

\section{1}

Encuentro №. 104, 81-91, 2016

\section{Conversaciones entre Fernando Cardenal Martínez y Citlali Rovirosa-Madrazo del libro sobre el Papa Francisco y Laudato Si': "Francisco. Entre la ciencia y la teología moral: Tierra, revolución y destino común”}

\author{
Juan Hernández Pico, SJ*
}

Fernando Cardenal y yo mantuvimos una amistad que fue haciéndose muy íntima y profunda con el correr de los años. Lo había conocido en 1963, cuando César Jerez y yo terminamos la etapa de formación como maestros en el Colegio Javier de Panamá y, antes de ir a estudiar teología en Frankfurt, pasamos unos días juntos en Guatemala y nos hospedamos en el Liceo Javier. Fernando era maestro allí y nos dio un largo paseo por la capital. Me asombró la manera enormemente entusiasta como, mientras conducía el automóvil, nos habló de la educación y de la receptividad de sus alumnos. Aquel enorme entusiasmo fue también la
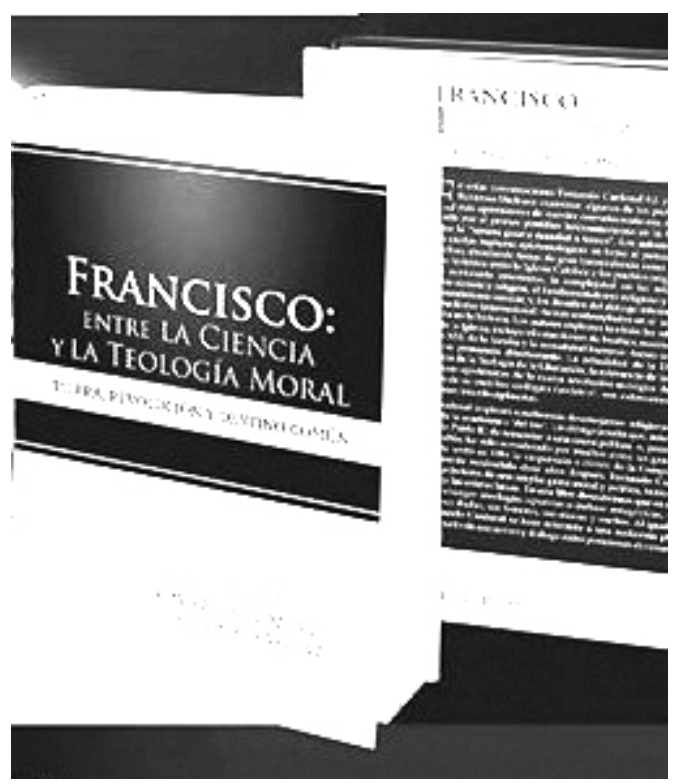
nota principal de otro encuentro cinco años después en México cuando también César Jerez y yo nos encontramos con Fernando recién ordenado sacerdote. Esta vez era la comunicación del fruto de sus primeros trabajos sacerdotales con jóvenes

Departamento de Teología, Universidad Centroamericana (UCA) José Simeón Cañas. San Salvador, El Salvador. 
universitarios. Las conversaciones de Fernando con Citlali están llenas de ese mismo entusiasmo. Y no pocas veces estalla también al responder a preguntas e inquietudes sobre la juventud. En la duodécima conversación habla Fernando de un encuentro con jóvenes en Granada, ciudad del Sur de España, y recuerda que les dijo: "Mi esperanza es que los jóvenes vuelvan a las calles a hacer historia”. Fue grande su sorpresa y su alegría cuando, al volver a Managua, se encontró sobre la Avenida Jean Paul Genie una gran manta colgada de lado a lado con el mismo letrero: "Mi esperanza es que los jóvenes vuelvan a las calles a hacer historia. Fernando Cardenal". Es fácil comprender esa alegría, cuando sabemos que brotaba de un corazón como el de Fernando que, cercano a su muerte, podía decir a su entrevistadora, hablando sobre si el sufrimiento extremo puede ser razón para pensar en la eutanasia: "El sufrimiento puede ser llevado con gran humanidad. Te lo dice con sencillez una persona que ha sufrido dolores permanentes de cabeza la mayor parte de su vida." Sufriendo así, Fernando nunca dejó de vivir con una alegría entusiasta como si tuviera las mismas energías de su juventud.

\section{Los temas de estas conversaciones}

Los temas con los que se atreve Fernando en estas 16 conversaciones son muy numerosos y nada fáciles. De acuerdo al título del libro en que han sido recogidas estas conversaciones - "Francisco"-, empiezan tratando el tema del Papa y los dos Sínodos sobre la familia, el extraordinario en 2014 y el ordinario en 2015. Sigue el pontificado mismo de Francisco. El tema lleva a rememorar la relación de Fernando con Juan Pablo II y la objeción de conciencia que el jesuita presentó cuando le fue planteado el mandato de dejar el Ministerio de Educación en 1984. Sabemos que esa objeción de conciencia le costó la expulsión de la Compañía de Jesús. Las conversaciones continúan tratando los grandes errores y pecados de la Iglesia así como también sus aciertos y su rostro solidario, donde Fernando enfatiza que Jesús de Nazaret es el fundamento de la Iglesia y la razón de la firmeza de su propia pertenencia a ella. Comienza en seguida el tema de los avances sociales de la Iglesia de hoy en contraste con su permanente conservadurismo en el campo de la moral sexual y de la vida. Siguen los temas de la homosexualidad y el ejercicio de la sexualidad, sobre los cuales habló ampliamente en una de sus entrevistas con Carlos Fernando Chamorro. Irrumpe la comparación entre dos papas: Juan XXIII y Juan Pablo II, a los que luego se añade el Arzobispo mártir Romero. Viene después la acusación de la ONU contra el modo como la Iglesia trata el tema de los sacerdotes pederastas. Vuelve la cuestión del aborto y entra el tema de los anticonceptivos y la ultimidad de la conciencia. La moralidad de los líderes revolucionarios en Nicaragua pasa luego a primer plano.

La primera parte del libro termina en la novena conversación con el tema del celibato como asunto personal de Fernando y como problema de los sacerdotes diocesanos, pero culmina en una lamentación de Fernando por lo que él experimenta como ausencia de Dios entre los pobres. La segunda parte del libro discurre a través de otras siete conversaciones. En la décima Fernando trata lo improbable de que tenga que plantear otra vez en su vida una objeción de conciencia y discute 
la problemática de la legitimidad de la violencia revolucionaria. Después repiensa Fernando el compromiso político como posibilidad de ejercicio del mayor amor y la contradicción en la política entre la corrupción y la honestidad. La duodécima conversación está centrada en las razones de la esperanza de Fernando en la juventud y el sentido del llamado del papa Francisco a los jóvenes a "hacer lío". Otros dos temas intervienen alrededor del fracaso o no del socialismo y la vigencia de la utopía así como la contradicción entre una América Latina con la mayor población católica y la mayor desigualdad entre ricos y pobres. Y finalmente, una reflexión sobre si la elección de un papa latinoamericano supondrá el fin del eurocentrismo. En la décima tercera conversación aparecen varios temas. La manipulación de la Iglesia por las clases dominantes, la existencia y el alcance de la lucha de clases así como el programa de "austeridad solidaria" para llegar a una nueva sociedad y su postura frente al mercado. Pero también la redefinición del rol de Fernando con la juventud. La décima cuarta conversación se centra en las polémicas alrededor del evolucionismo y el cambio climático y la postura de la Iglesia ante la ciencia temas tratados más extensamente en la Tercera Parte del libro escrita por Citlali. La penúltima conversación trata temas dispares: la apertura de los archivos vaticanos sobre el Holocausto, la postura de los jesuitas frente al diálogo interreligioso, el tema del origen de la vida y su sacralidad frente a la eutanasia. La décima sexta y última conversación es tal vez la más multi temática. La postura de la Iglesia frente a la mujer, el futuro de la teología de la liberación, la discusión sobre el desarrollo del embrión humano y su personalización así como los posibles efectos sobre la interrupción del embarazo y el diálogo inter religioso y la búsqueda de la paz.

\section{Las cinco convicciones mayores de Fernando Cardenal}

No cabe la menor duda de que Fernando se enfrentó en estas conversaciones con una multitud de temas, que a cualquiera le habría inquietado. Soy testigo de que los estudió con una gran responsabilidad. No pretendió nunca sorprender, por decirlo así, con un jonrón que se saltara las vallas por el centro del estadio. Sabía que los temas eran peliagudos y sabía que su nombre iba a atraer a muchos lectores. En no pocas ocasiones dialogamos juntos sobre no pocas de sus respuestas.

Quería él dejar constancia en su tratamiento de varias convicciones suyas muy enraizadas. La primera y la más importante de todas, la prioridad en su corazón de su amor a Jesucristo y de la centralidad del Evangelio de Jesús de Nazaret en todas las decisiones de su vida. La segunda, su amor por la Iglesia y su lealtad hacia ella, a pesar de su clara conciencia de las muchas veces que esta Iglesia había fallado históricamente en el seguimiento de Jesucristo. La tercera, la fe en la juventud como fuerza para mejorar el mundo y en la educación de la juventud como instrumento eficaz para movilizar esa fuerza.

La cuarta, ya en la madurez de sus 35 años, el compromiso total con los pobres y con la lucha por su liberación y por la justicia, sellado ante ellos con juramento en un barrio marginado de Medellín al final de su último año de formación espiritual. La quinta, la concreción de ese juramento en su participación en la lucha revolucionaria para derrocar la dictadura somocista y en la construcción de una patria soberana, socialista y democrática a través de la cruzada de alfabetización, la 
dedicación a la juventud sandinista y la entrega en el Ministerio de Educación.

Hay una frase en el libro que estoy presentando que no sintetiza, pero sí enfatiza estas convicciones: "yo he sido una persona motivada profundamente por el mensaje de Jesús que me llevó al compromiso por los pobres y ese compromiso me llevó a la Revolución” (p.161).

\section{La objeción de conciencia}

Naturalmente, en el tratamiento de todos estos temas, hay varios que destacan especialmente. Tal vez el más importante es uno de los más conocidos en su vida. Me refiero a la objeción de conciencia frente al mandato del papa Juan Pablo II de dejar su afiliación al Frente Sandinista y su trabajo en el Ministerio de Educación. Fernando sabía muy bien que en el canon 287, parágrafo 2, se daba la posibilidad de una excepción -cuando "lo exijan la defensa de los derechos de la Iglesia o la promoción del bien común”- para la prohibición de que los clérigos participen en actividades partidarias o sindicales, pero sabía también que Juan Pablo II no iba a permitir esa excepción porque veía a la Revolución Sandinista como equivalente a los regímenes políticos dependientes de la Unión Soviética, incluido el de su propia patria, Polonia, y pensaba que la Iglesia en Nicaragua debía luchar contra el Sandinismo y no colaborar con él. Fernando, en cambio, estaba convencido de que con la Revolución Sandinista se estaba dando una situación histórica novedosamente original por la participación de los cristianos en ella y la libertad religiosa consagrada en las leyes. Para Fernando, mantenerse sirviendo a la revolución, siendo sacerdote y sirviendo al frente de la educación del país, era el camino más eficaz para cumplir con su juramento en aquella hora histórica. Pedirle que abandonara su servicio a la Revolución era como "tocar sus dos grandes absolutos, que no negocio con nadie: Dios y los pobres." Fernando estaba además convencido de que los obispos en Medellín se habían hecho eco de una tradición vigente desde Pío XI sobre el valor cristiano de la participación en la acción política como un deber cristiano y una de las formas más nobles y eficaces del amor (Justicia 16), precisamente por su servicio al bien común. Para él además todo se enraizaba en el recuerdo experiencial de la parábola del Buen Samaritano y la voz que en ella escuchaba: "Andá y hacé vos lo mismo."

\section{La esperanza en la juventud}

Otro de los temas recurrentes en las conversaciones es la juventud, los jóvenes. Fernando habla aquí de su esperanza en la juventud desde su experiencia más profunda: cuando en Granada "yo dije lo que esperaba de ellos es simplemente porque yo conozco a los jóvenes, estuve con los jóvenes aquí en Nicaragua, yo participé y viví el Movimiento Cristiano Revolucionario que fundamos en la UNAN de Managua en la lucha contra la dictadura, estuve en la campaña nacional de alfabetización con sesenta mil jóvenes en la montaña, luego estuve cuatro años con la Juventud Sandinista (en ese entonces la juventud de la Revolución).” A esa esperanza añade Fernando otra experiencia, la experiencia de la alegría. Y dice que para los jóvenes "mi mensaje central fue...siempre: ¡sean felices!" Fundamentaba esta 
felicidad en tres fuentes. Primero, en "Aristóteles, que decía que "la finalidad de la Ética era la felicidad' y que "los sabios son felices porque aman". Segundo, en "Jesús, que nos enseñó que había más felicidad en dar que en recibir". "Lo que yo sigo haciendo ahora -dice Fernando- es buscar la manera de unir el espíritu de entrega, el espíritu de servicio, con la alegría”. Por eso, en tercer lugar, se refiere a Rabindranath Tagore y su pequeño poema: "Dormía y soñaba que la vida era alegría. Desperté y vi que la vida era el servicio. Serví y vi que el servicio era la alegría.”

Fernando añade: "los jóvenes tienen toda la fuerza y la capacidad para hacer cosas maravillosas en su país, en su comunidad, en el mundo. Esto sucede cuando se dan dos condiciones: primero, tener una meta grandiosa, una importante y grandiosa meta para el país, por difícil que parezca alcanzarla; y segundo, que quienes están llamando a estos jóvenes para cumplir con dicha meta (o movilizarse por dicha causa), tengan verdadera autoridad moral.” Eso creía Fernando que sucedió en Nicaragua con la Cruzada Nacional de Alfabetización.

Es notable que a Fernando, al final de su vida, la Carta Encíclica Laudato Si' de Francisco "sobre el cuidado de la casa común" le pareció que contiene una "nueva gran causa... proteger paralelamente a la naturaleza y a los pobres..., una causa grandiosa..., una empresa y una doctrina para el bien común, y viene precisamente de una de las pocas personas en el mundo que hoy tienen esa gran autoridad moral”. Incluso soñó, junto con su interlocutora y amiga, Citlali Rovirosa-Madrazo, en convocar "a los jóvenes para impulsar una 'coalición educativa' inspirada en la Laudato si'..., una campaña mundial de educación ecológica...” Contaba para ello con la permanencia del grito animoso y perturbador del papa Francisco en su primer encuentro multitudinario con jóvenes en Río de Janeiro, apenas tres meses después de ser electo: “Hagan lío!” Fernando pensaba que ese “ihagan lío!” significaba que "se muevan, que opinen, que participen, que sacudan las estructuras arcaicas y vacías... que propongan... que no tengan miedo... Jesús también vino a crear líos... un lío tan grande... que los dirigentes, sumos sacerdotes... decidieron asesinarlo." En un país como Nicaragua, donde hoy, según escucho, la naturaleza está siendo atacada en una forma inmisericorde, donde las grandes extensiones de la Costa Atlántica están siendo saqueadas de bosques maravillosos, donde se pretende entregar al neocapitalismo chino la construcción de un canal que puede acabar con la reserva de agua dulce del Lago Cocibolca, ¿no parece que se justifica el entusiasmo de Fernando con la defensa de la tierra y de los pobres, que hace Francisco en la Laudato si? ¿No parece que podría articularse alrededor de una causa política inmanente y trascendente a la vez?

\section{Temas morales espinosos en la Iglesia}

No es improbable, sin embargo, que el interés por estas Conversaciones de Fernando se enfoque intensa y particularmente alrededor de los temas que tocan el aborto, los anticonceptivos, la homosexualidad, el celibato en la Iglesia, etc. Los temas que podríamos llamar moralmente "espinosos”. Tratémoslos también en esta presentación.

Al abordar estos temas, Citlali Rovirosa-Madrazo le propone a Fernando una 
especie de paradoja: la Iglesia Católica ha sido muy progresista y avanzada en su enseñanza moral social pero, ¿por qué sigue siendo muy conservadora y retrógrada en su enseñanza moral personal, sobre todo alrededor de la vida y el sexo? Respecto del aborto, Fernando tiene convicciones muy claras. Habla del aborto, que llama "libre" y afirma que la Iglesia lo rechaza fundamentalmente para ser fiel a ese imperativo moral que brota del corazón humano: “¡no matarás!”. Se refiere también al nuevo contexto en que el papa Francisco lo trata: la incompatibilidad de "la defensa de la naturaleza con la justificación del aborto" (Ls' 120). Comenta Fernando: "La defensa y protección de la vida es importante en todos los niveles, la vida humana es sagrada en todas sus manifestaciones y estratos: la vida de los migrantes, la vida de los pobres, la vida de los ancianos, la vida de las víctimas de trata de personas, la vida de los enfermos de sida o malaria, y, la vida misma de las especies que habitan nuestro planeta, 'nuestra casa común', como la llama en su Carta Francisco.

Un jesuita chileno, socialmente muy avanzado y también antiguo profesor de moral, Pepe Aldunate, que acaba de cumplir 99 años, se expresó así hace dos años: "Es cierto que no podemos estar de acuerdo con el aborto sin apellido. Nadie lo está. Es una vida humana que se sacrifica de forma cruenta. Y es cruenta, no solamente con la criatura, sino contra la mujer, porque muchas veces la deja dañada de por vida.” Y añade: "Pero la solución no es prohibirlo, como ahora, porque eso ha demostrado que no soluciona el problema, Es más, lo acrecienta... En los únicos países donde hay más abortos es donde está prohibido. Ignorar este problema es realmente criminal". Fernando habla con la misma claridad sobre el aborto terapéutico, practicado en circunstancias médicas específicas, "cuando no se puede salvar dos vidas y se opta por salvar la vida de la madre... Solo este -dice- es aceptado en documentos de algunas conferencias episcopales basados en la doctrina tradicional del 'doble efecto’ Esto significa que para la Iglesia es mejor salvar una vida que dejar que se pierdan las dos (la de la madre y la del feto)"; aunque no piensan así los obispos y las leyes de Nicaragua. Habla luego de otro aborto no aceptado por la moral católica, el aborto llamado "eugenésico", cuando el feto viene con "malformaciones drásticas que prevén una vida enferma o incluso inhumana para el feto ya nacido". Fernando se da cuenta de que muchas feministas consideran que es preciso extender el debate a la "interrupción voluntaria del embarazo en caso de malformaciones genéticas graves" e informa de que una amiga suya que trabaja con mujeres violadas que sienten que no pueden aceptar el embarazo, le ha ayudado a comprender "el drama que viven estas mujeres en los barrios de Managua y en todo el país”. También el moralista ya citado, el anciano jesuita Pepe Aldunate, tocó este punto: él está de acuerdo con el derecho al aborto "en caso de violación. Hay mujeres que al ser violadas quedan tan traumatizadas que no pueden tener un niño que para ellas les recuerda a su violador. Uno no puede obligarlas a pasar por ese calvario. Una violación es un trauma muy grande." Sintetizando, Fernando dice que cree que "la postura del Papa seguirá siendo de rechazo rotundo al aborto, pero no en el tono de condena que ha caracterizado a muchos en la Iglesia", sino, "como dice Francisco en la Evangelii Gaudium" (214), acompañando "a las mujeres para quienes el aborto se les presenta como una solución rápida a situaciones de profundo dolor".

Toca también Fernando el tema de la homosexualidad. Recuerda sus 
"tiempos de estudiantes: en el Colegio Centroamérica, era interno, éramos nosotros homofóbicos, éramos muy ignorantes... veíamos a la homosexualidad como un crimen... Una vez un chavalito contó que un compañero lo había intentado seducir y lo había invitado a tener relaciones -¿qué fue lo que hicimos nosotros?- esperarlo en el comedor para lincharlo... ¡Y lo linchamos!” Hoy, en cambio, Fernando nos deja esto escrito: "algo que tiene que entender la Iglesia es que, mientras queramos seguir siendo cristianos seguidores de Jesús, debemos respetar a los homosexuales..." Y continúa Fernando: "Yo me hago una pregunta delante de Dios... ¿podrá el Dios revelado por Jesús, el Dios del amor, el de la misericordia, la ternura, la piedad, nuestro buen Padre Dios, exigirle obligatoriamente a un joven que nació homosexual (o lesbiana) que guarde un celibato impuesto hasta el día de su muerte..., que nunca en toda su vida tenga una pareja?... Algunos científicos -continúa Fernando- han encontrado que la homosexualidad es una predisposición genética, aunque entiendo que no hay consenso en este tema y que el debate y las investigaciones continúan. Yo no puedo opinar científicamente...pero lo que sí...puedo decir es que, en mi experiencia pastoral la mayoría de las personas que se consideran homosexuales, lo son por nacimiento. Pero lo más importante es que, nosotros como católicos, creemos que a todos y a todas los ha creado Dios... ¿discriminarlos es un proceder humano digno de un Dios, no solo misericordioso, sino también fiel a su creación?".

Finalmente, Fernando aborda el tema del matrimonio entre personas del mismo sexo, y reconociendo que en los recientes Sínodos sobre la familia se ha reafirmado el matrimonio como sacramento para parejas de distinto sexo y que no es probable un cambio en este punto, él quiere aclarar que "una cosa es el matrimonio, que tiene una larga historia cultural y eclesial de referirse exclusivamente a la unión entre una mujer y un hombre, y otra cosa es que la Iglesia pudiera tal vez llegar a bendecir la unión entre parejas del mismo sexo. Esa bendición...es...algo diferente de un sacramento propiamente, pero algo que se otorga en nombre de Dios." Termina Fernando: "Yo no creo que hoy... Jesús de Nazaret" negaría "a estas parejas una bendición en nombre de Dios."

Finalmente se enfrenta Fernando con el famoso y espinoso tema de los anticonceptivos. No recuerda cómo el Papa Pablo VI retiró este tema de la agenda del Concilio, pero sí recuerda cómo el mismo papa formó una comisión que reflexionara el punto y le diera su opinión, y cómo la mayoría de esa comisión aconsejó a Pablo VI que, además del uso de los tiempos no fértiles de la mujer para el acto sexual, se aceptaran en la Iglesia los medios químicos para inhibir la fertilidad, como por ejemplo, la píldora. Todos sabemos que en la encíclica Humanae vitae el mismo Pablo VI mantuvo la prohibición de la píldora, inaugurando así una de las crisis más serias de discrepancia con una multitud de parejas católicas en todo el mundo. Fernando recuerda que "no pocas conferencias episcopales escribieron sobre el tema" después de publicada la Humanae vitae y aceptaron "que en último término la decisión recaía en la conciencia de las parejas, prolongando así la doctrina del Vaticano II (Gaudium et Spes nn 15-17) sobre la conciencia como último santuario de las decisiones humanas -única manera de respetar tanto la dignidad como la libertad de las personas humanas.” Fernando expone en su séptima conversación que en su trabajo pastoral él ha procedido "estando a favor del aborto terapéutico, y estando a favor de los anticonceptivos. Pero...nunca hablé en público -dice-ni escribí 
exponiendo mis ideas en estos más de sesenta años de vida jesuítica." Continúa Fernando afirmando que le ayudó mucho una famosa frase de San Agustín: "En las cosas necesarias, obediencia. En las cosas discutidas, libertad. Y en todo caridad"...Como el tema del aborto terapéutico y los anticonceptivos eran discutidos en la Iglesia, yo procedí con absoluta libertad.”

Como ya he referido anteriormente, las Conversaciones tratan muchísimos puntos más. Por ejemplo, Fernando interpreta la canonización conjunta de Juan XXIII y Juan Pablo II que hizo Francisco como una muestra de su preferencia por el modo de ser Papa de Juan XXIII, puesto que fue él quien decidió añadir a la canonización de Juan Pablo II, que ya encontró encaminada, la del Papa del Vaticano II, sin esperar al milagro que aún no había sucedido por su intercesión. Habla así ampliamente de la Teología de la Liberación, que, siendo discutida en la Iglesia, sintió que podía seguir con plena libertad. El P. José (Pepe) Aldunate, a quien acabo de citar en esta conversación con ustedes, acaba de publicar, a sus 99 años, un artículo magnífico en Religión Digital, recordando que ha sido la Teología y la Pastoral de la Liberación la que ha renovado la vida de la Iglesia en América Latina y se atreve a decir que eso está mostrando el Papa Francisco con su palabra y sobre todo con su práctica, porque el corazón de la Liberación es la opción por los pobres y el amor a ellos y ellas. Habla también de su convicción de que el celibato de los sacerdotes diocesanos no debe seguir siendo obligatorio. También se separa con claridad y firmeza de cualquier atribución de fundamentalismo y terrorismo a la fe musulmana. Se muestra en favor de que sean abiertos los archivos vaticanos sobre el holocausto. Y se muestra en profunda sintonía con el diálogo entre las religiones. Habla de su celibato personal con una franqueza admirable. Dado el tamaño normal de una presentación debo dejar otros varios temas.

No sería fiel a las conversaciones de Fernando, sin embargo, si no regresara a una de las preguntas primeras que le hizo Citlali. ¿De qué se trata cuando Fernando, representante en esto de lo mejor de la Iglesia Latinoamericana de Medellín y Puebla, privilegia su compromiso con la liberación de los pobres y la lucha por la justicia? Se trata del corazón mismo de Fernando, de lo que él sintió como su conversión en medio del barrio marginado de Medellín, donde los pobres y su sufrimiento le robaron el corazón. Es ahí donde se encontró de verdad en ellos con el rostro y la persona de Jesucristo: "Lo que hiciste con estos mis hermanos, conmigo lo hiciste" (Mt 25, 40). Ahí se fundieron sus amores y su amor a Jesucristo se volvió amor absoluto a los pobres de la tierra y compromiso insobornable por su liberación y la lucha por la justicia en Nicaragua y en este mundo. Yo les pido que lean, en el libro que estamos presentando, la "Carta a Dios desde América Latina" que Fernando incluye en su décima conversación. Les voy a transcribir aquí solo unas líneas de lo que escribió cuando vio que algunos niños, sus vecinos y amigos, estaban comiéndose los desperdicios dejados a la puerta de la propia comunidad de Fernando:

¿Por qué se estaban comiendo nuestra basura? Muy obvio, porque tenían hambre... La única certeza de los pobres era que su vida no iba a cambiar. Eso si era seguro... Señor y Dios mío, el gran amor de mi vida, yo he sido testigo de tu maravilloso amor y tu perdón a lo largo de toda mi larga vida... Pero ¡qué dolor para mí, mi Señor, mi Papá, que a mis amigos pobres 
no les puedo hablar de que Vos los amás a ellos, con predilección. No lo entenderían [desde] su realidad diaria de pobreza y sufrimiento... Nunca les he podido hablar de tu amor a ellos... ¿Por qué estás ausente de los pobres de hoy, de mis pobres?

En su carta, Fernando había contado antes esto: "Cuando vivía en el barrio marginado "Edgar Munguía” de Managua, a una de mis vecinas le secuestraron a su hijita de catorce años, ella sospechaba que era para venderla para la prostitución. Muerta en llanto estuvo haciendo gestiones en la Policía y en varias emisoras intentando encontrar a su hija. Llegó a mi casa y me abrazó llorando contándome lo inútil de sus gestiones. Y me dijo: "Lo bueno es que Dios no nos abandona nunca”... ¿Quién más abandonada que esta pobre mujer de mi barrio? Su marido era lisiado de guerra, ella [vivía] enferma, no tenían trabajo [tenía varios hijos] vivían en la extrema pobreza [...]. Pero ella sentía en medio de su pobreza y su dolor la presencia de Dios que la sostenía y consolaba."

Fernando no se daba cuenta de que Dios sostenía y consolaba a esta mujer por su propio medio, por medio de Fernando. Todos recordamos que cuando Fernando no pudo vivir ya en el barrio Edgar Munguía y se trasladó a Villa Carmen, en la UCA, desde ese barrio acudían a él muchas familias, 22 dice él mismo, y para todas tenía una ayuda durante años. El dice en sus conversaciones que si hubiera tenido acceso a cambiar las cosas políticamente podría haber ayudado con más eficacia aún. Pero, no obstante, él ayudaba. Y a través de él Dios respondía a su queja y acompañaba en la historia de cada día a algunos de los pobres a quienes él había hecho su juramento. Dios estaba cerca de ellos por el trabajo de Fernando en Fe y Alegría y con esas familias del Edgar Munguía. Por eso le dijo el Superior General de la Compañía cuando volvió a admitirlo: "Usted ha sido coherente con sus amores". Y por eso pudo decir él en sus conversaciones: "Aquí estoy yo trabajando todos los días, a pesar de que ya cumplí los 81 años y a pesar de que tengo muy mala salud, pero con mucha fe y con una gran alegría, con la satisfacción de poder ayudar a cambiar la vida de los pobres... y estaré hasta que caiga”.

\section{La semejanza entre Fernando y Dorothy Day}

Voy a terminar, pero antes quiero evocar la gran semejanza entre Fernando Cardenal y una santa laica estadounidense del siglo XX, santa en la realidad y ya Sierva de Dios, el primer paso hacia la canonización. Nació en 1897 y murió en 1980. Fue bautizada primero en la Iglesia Episcopaliana, la rama estadounidense de la Confesión Anglicana. Se apartó de la Iglesia y de la fe por la incoherencia que veía: aunque ayudaban a los pobres con caridades, no asumían sus luchas. Se hizo anarcocomunista y, como periodista, practicó la lucha de clases y también se integró al movimiento feminista de izquierda y conoció la cárcel en varias ocasiones. El amor, la maternidad de su hijita Tamara Teresa, la contemplación de la naturaleza negada a los pobres, le llevaron a la fe católica, porque -decía- en ninguna otra Iglesia los líderes religiosos están tan cerca de los pobres. Sobre todo esto escribe Dorothy Day en "La Larga Soledad". 
Al fin fue bautizada de nuevo condicionalmente por si el anterior bautismo no había sido auténtico. Se encontró con un campesino francés, Peter Maurin, emigrado a los Estados Unidos, y profundamente amigo de los pobres. Juntos fundaron un movimiento, The Catholic Worker, "El Obrero Católico". Peter Maurin, campesino y teólogo, quería volcarse en amor a los pobres y oprimidos y predicaba la creación de una sociedad que permitiera que la gente fuera más buena, porque eso les haría más felices. Dorothy Day quería hacer eso y además luchar estructuralmente por la justicia con los obreros, por la fuerza de los sindicatos y la lucha por salarios dignos. Ambos eran pacifistas y se opusieron a todas las guerras, incluida la Segunda Guerra Mundial y luego el armamentismo nuclear.

Dorothy Day fue acusada de fomentar la lucha de clases. Respondía, con San Agustín: "La botella siempre huele al licor que contuvo una vez". The Catholic Worker, El Obrero Católico, fue a la vez una cadena de casas de acogida y comedores para obreros y obreras sin trabajo, un periódico militante, y un movimiento que participaba sin odio en huelgas, piquetes y manifestaciones. Además inspiraban en su periódico, con "las armas del periodismo" un pacifismo estructural como lucha de clases porque la guerra siempre acaba favoreciendo a los ricos, pero enfatizaban también las obras de misericordia: dar de comer a quienes tienen hambre, visitar a quienes están en la cárcel, dar acogida a los inmigrantes, etc. Cuando vi a Fernando cumpliendo su juramento de luchar por los pobres, primero, en la revolución con alfabetización y educación; ofreciéndoles, luego, educación de calidad en Fe y Alegría; y atendiéndolos en sus tardes de ancianidad materialmente en su pobreza, y consolándolos, comprendí que él en Managua, como aquellos grandes cristianos del "Obrero Católico", Dorothy Day y Peter Maurin, en los Barrios del este de Nueva York, vio con un fogonazo de luz que cristianamente, es decir, humanamente, no hay lucha estructural por la justicia sin, a la vez, obras de misericordia, es decir, amor a los pobres manifestado en pan y compañía, en consuelo y magnanimidad.

\section{Breve nota sobre la tercera parte del libro}

Por cierto, Citlali reflexiona sobre el significado de que Francisco haya evocado a Dorothy Day en su discurso ante el Congreso de Estados Unidos (reproducido en el apéndice del libro). En su propia presentación de este libro en York, Citlali RovirosaMadrazo reflexionaba sobre los paralelismos entre el pensamiento de Dorothy Day (con el citado movimiento "El Obrero Católico"); y la encíclica Laudato si'. A su juicio, el legado de dicha escuela de pensamiento y práctica social está claramente presente en la doctrina social de la Iglesia Católica del siglo pasado y se extiende, en este siglo, a la encíclica Laudato si'.

Citlali Rovirosa Madrazo, además de entrevistar a Fernando Cardenal en la vida real y en este libro, ha reflexionado académicamente sobre algunas de sus respuestas. Destaca Citlali la incorporación de la ciencia al discurso ético en Laudato si'. Hace una lectura 'deconstructiva' sobre diversos discursos de la Iglesia a lo largo de la historia y explora lo que ella llama las grandes rupturas epistemológicas de la Iglesia Católica. Estudia cómo el obispo de Roma, Francisco, hace una revolución verdadera en la Iglesia precisamente por medio de una deconstrucción, un ejercicio 
de ruptura epistemológica del modo habitual de los papas de escribir sobre la justicia. Y ello uniendo paradigmáticamente la lucha para ayudar a la salvación de los pobres con el estudio y la proclamación de que se trata de una misma lucha con su combate para salvar la naturaleza. Así como sus repercusiones políticas, por ejemplo la creación de un concepto revolucionario, la ecología integral.

Movilizar a las universidades, organizaciones sociales, organismos y agencias internacionales, como UNESCO, para impulsar una campaña mundial de alfabetización ecológica fue el sueño de Fernando y Citlali, quien sigue buscando la manera de darle continuidad a esta iniciativa y hacerla realidad.

\section{"El sí era un héroe y un santo"}

Yo me he detenido y he bajado en esta presentación a la mina de las conversaciones con Fernando. La tercera parte del libro enriquece su totalidad con hondura políticoepistemológica.

Muchas gracias a Hispamer por publicar este libro, y a ustedes por promover con su presencia el valor de mantener viva la memoria de Fernando. "El sí era un héroe y un santo. Vivió pobre, luchó por los pobres, y murió pobre". Así me lo decía hoy un trabajador nicaragüense también pobre. Y muchas gracias a Citlali RovirosaMadrazo por la iniciativa de sus conversaciones con Fernando, que nos permitió asomarnos al gran corazón y la mente visionaria de este gran cristiano nicaragüense que vivió, soñó y actuó con los pobres y por los pobres de la tierra. 